\title{
A Nought Conviction Way to deal, by means of System Sanctuary
}

\author{
Nagender Yamsani, Yerrolla Chanti, Bura Vijay Kumar, SrinivasAluvala, Mahesh Dandugudum
}

\begin{abstract}
In the latest existence, we have seen an extension in the bring into play of remote frameworks in view of new sorts of correspondence. The online sanctuary has transformed into an intensely talked about subject in the system. People need to approach most of your coatings and resources wherever, at whatever point. , by means of the extension in the usage of Distributed figuring and IoT, the amount of related contraptions extends that subsequently in like manner increase the destinations of cybercrime. A fundamental distinction in outlook can help guarantee statistics and the entire framework. This thesis delineates what a nought conviction System is and shows a couple of thoughts driving this plan/thinking. nought conviction is a structure that has a standard that the whole thing in the interior or faint the framework isn't trustworthy until checked.
\end{abstract}

Watchwords: Dital sanctuary, Business digital Sanctuary, Nought Conviction System, Google Beyond Corp.

\section{INTRODUCTION}

Digital sanctuary is a fervently discussed point today on account of the rupture a lot of delicate data from enormous organizations. Which has casecond-hand an unavoidable issue on who we can confide in our information? In this way, the IT scenery has missecond-hand and the utilization of systems significantly has rise. The clients need to get to coating all over the place, unfailingly and in the company of this, we encompass a lot of delicate information on these systems/coating that e-criminals need to have the option to benefit, by means of . Thus, the sanctuary model needs to help this development to protect client information. As indicated by the creators [1], the regular model typically utilized has at the top of the priority list construct a divider among trusted and untrusted assets, neighborhood arrange and the web for instance. Also, as indicated by the workstation sanctuary association (CSI), around 60 to 80 centum of system abuse episode is started contained by the system [2]. , by means of these wants comes a sanctuary engineering called "nothing Trust" that changed into created by method for of Forrester Research [1]. Nothing, dislike the predictable rendition as its standard "in no way consider, for the most part affirm where both inward and outer systems

Revised Version Manuscript Received on 10 September, 2019.

Nagender Yamsani, Department of Computer Science and Engineering, S R Engineering College, Warangal Urban, Telangana, India. (email: nagendar.yamsani@gmail.com)

Yerrolla Chanti, Department of Computer Science and Engineering, S R Engineering College, Warangal Urban, Telangana, India.(email: yerrollachanti308@gmail.com)

Bura Vijay Kumar, Department of Computer Science and Engineering, S R Engineering College, Warangal Urban, Telangana, India.(email: vijaykumar.bura@gmail.com)

SrinivasAluvala, Department of Computer Science and Engineering, S R Engineering College, Warangal Urban, Telangana, India.

Mahesh Dandugudum, Department of Computer Science and Engineering, S R Engineering College, Warangal Urban, Telangana, India. can't be trusted. This guideline is the reason for diminishing the danger of assaults now not most straightforward outside but rather also internal. This model expedites new gauges an approach to structure an organization network which incorporates division portal, which licenses expanding the smaller scale division of a network, by means of the goal of getting additional perceivability over all guests by looking at a wide range of clients and gadgets that join inside the sort out. Past Corp is an instance of a 0 think designing ward, by means of the guide of Google that empowers agents to work the majority of the extra effectively in any territory, by means of out the necessity for a traditional VPN.

\section{SYSTEM SCENE AT FIRST}

The presence of the main PC frameworks, organizations would be progressively "secluded" which alleviated the quantity of assaults concentrating on their endeavors to limit get to just inside the organization by various leveled levels. Since nowadays the wellbeing models created have concentrated on isolating the "confided in assets" from the "untrusted assets" utilizing layers of insurance to fabricate advanced edges. The as indicated by the creator [3] the customary edge sanctuary reckon to the firewalls, VPN's and net entryways who needs to transaction, by means of agent's mastery lacks, over-load, and a routinely broadening number of cloud coatings and mobile phones which prompts a development in the attack surface of dital criminals. The creating of conveyed processing and the snare of things have cause these periphery to cleared out. What might we have the option to express that the standard model is never again viable, by means of that model as much as we put assets into digital sanctuary of our association, new and continuously refined ambushes are moved aligned, by means of our shield so we should look at digital sanctuary not as an endeavor but instead as a need after some time. Concurring [4] it is evaluated that dital crime target enlarge amazingly in light of the nearness of a reliably creating creation of related inhabitants (figure 1). 


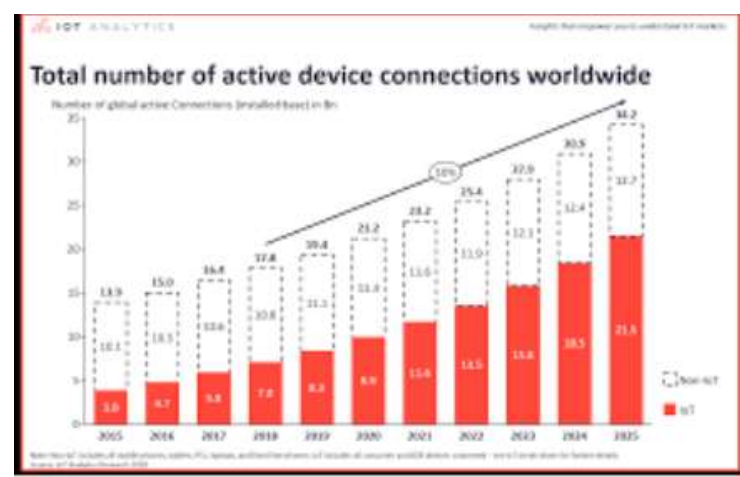

Fig.1. Growing of connected people .

\section{Effect of Cyber sanctuary:}

, by means of the expansion in the quantity of gadgets associated, by means of the Web and subsequently more assault region for cybercriminals, the fiscal qualities engaged , by means of cyber sanctuary has been expanding [4]. Digital sanctuary is connected to verifying information and computerized chance structures. intimidation container be second-hand as (malware, deliver product, phishing, worms) these missiles are dynamically best in class and modernized and can be purchased expecting almost no exertion together, by means of this, associations have a "dependable things" come, by means of in reach of to manage fight those risks, which we determination see later in this piece of writing this isn't commonsense in light of the fact that this representation is exorbitant and multifarious. The digital sanctuary advertises is depended upon to touch base at 170 lacks by $2020[5]$.

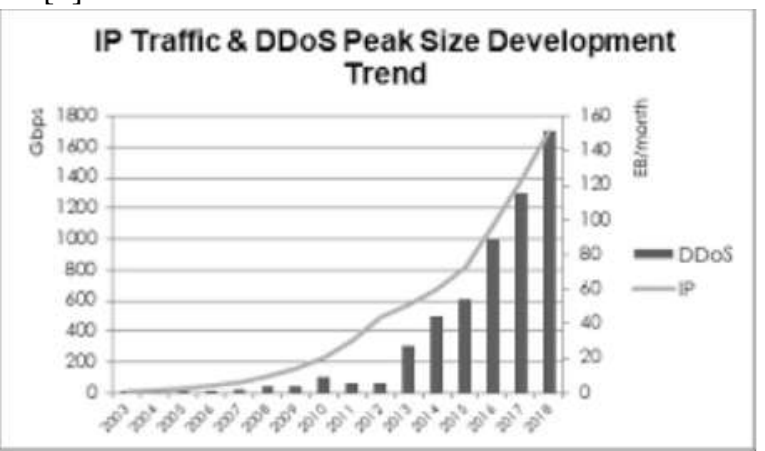

Fig.2. Advancement of transmission capacity utilized for major DDoS

\section{NOUGHT CONVICTION BASICS SEEING THAT CUSTOMARY FORM \& RESULTS}

Continuously pragmatic, we can't give the sanctuary of our affiliation an opportunity to be relied on essentially on a firewall or interference revultion system. The Nought Conviction is a sanctuary model made by at Forrester asks about which have the standard of "by no means conviction, reliably affirm, this building is planned to ease risks inside the framework unequivocal statistics or worldly goods, by means of the objective that inexorably coarse set of laws can be associated. According .[6], Nought Conviction isn't building frameworks, fogs, or end sectors progressively trustworthy; is to forgo trust from cutting edge system, conviction is matched, it's on or off which isn't equivalent to this present reality partner, by means of inhabitants. So Nought Conviction is about how you think and there is no solitary prescription for realizing this sort of designing. When edifice a framework, by means of Nought Conviction DNA you need to recall the going, by means of subjects: [6] Guarantee all statistics are strongly gotten to reliant on customer and territory The usage of admittance direct is immovably urged/obligatory Examine de kindling of all interchange This is critical in our present reality where compactness is continuously overall, by means of remedy, PDAs, PCs, and Internet of things contraptions getting to the web. These contraptions necessitate getting to these benefits in a sheltered technique

\section{A. Nought Conviction Design:}

by means of this we be capable of articulate that never again subsist a conviction in crossing point in our diplomacy, never again subsist a conviction in framework, and never again exist accepted customers and this is a huge thought when we need to move groups beginning, by means of one spot then onto the following. If we give the impression of being at the regular representation (figure 3) we have a couple of stratum of the framework that we plant a couple of stratum of sanctuary contraptions. This over the stretched haul making the framework overpowering, unmanageable, hard to be cautious and reliably placed assets into new diplomacy after some time.

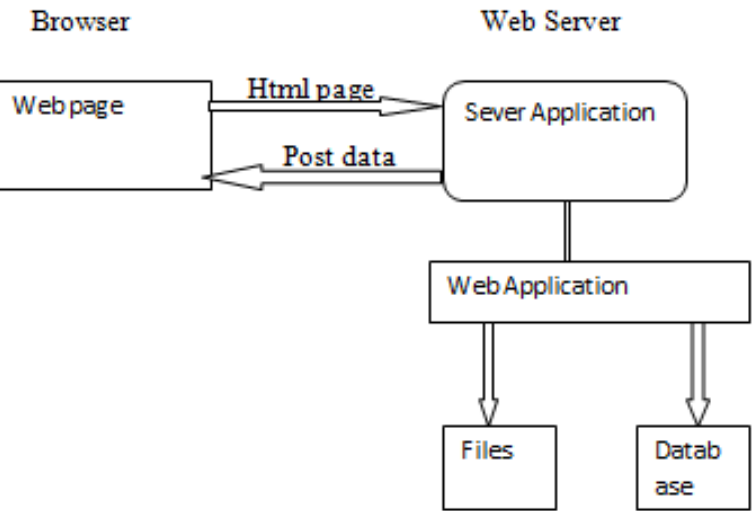

Fig.3. Conventional Design base on.

So Nought Conviction representations redraw the framework and make another idea of division entry. This thought is attempted to give attention to all of the advantages that are second-hand in a propelled framework like, contented filter, get the opportunity to be in command of, firewall, cryptographic locomotives, group sending. This sort of division is second-hand in a disconnected way, is flexible and can conform to a industry, by means of out remaking the entire framework configuration. Nevertheless, if an association needs to configuration the framework, it needs to do commencing the back to front, what will allow having a framework that changes and creates, by means of a sanctuary ADN where all bundles can be passed on in an ensured way. This division gateway representation is painstaking by [7] as a front line firewall, in view of the fact that it is made to fabricate the littler scale division of the frameworks, winding up entirely adaptable, by means of respect to being flexible, changing in accordance, by means of a wide scope of 
business and virtualization-pleasing.

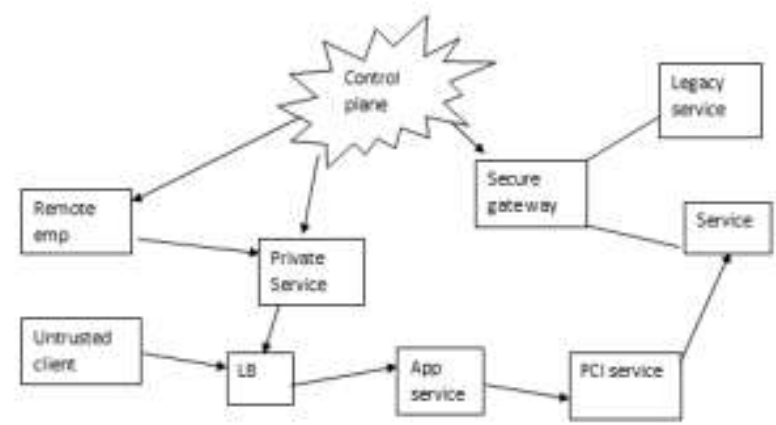

Fig.4. Nought Conviction Design dependent on .

In the shape higher than it is addressed a division entry in a fundamental way construction the severance in littler scale division (MCAP) so it is less complex to evaluate all the interchange of the framework. Along these lines, , by means of the division and forefront firewalls, we can control who, what, where and when an important person get related in the framework. following a patron is confirmed, the advantages be obliged to be solidly administered. The instinct following this is to thwart parallel advancement inside the framework in the wake of being undermined this decreases the extent of smash up casecond-hand. The term firewall, for this circumstance, can't be confsecond-hand, by means of the manner in which that we have to place near the edge of the framework in light of the fact that the division portal be required to be placed in the point of convergence of the framework.

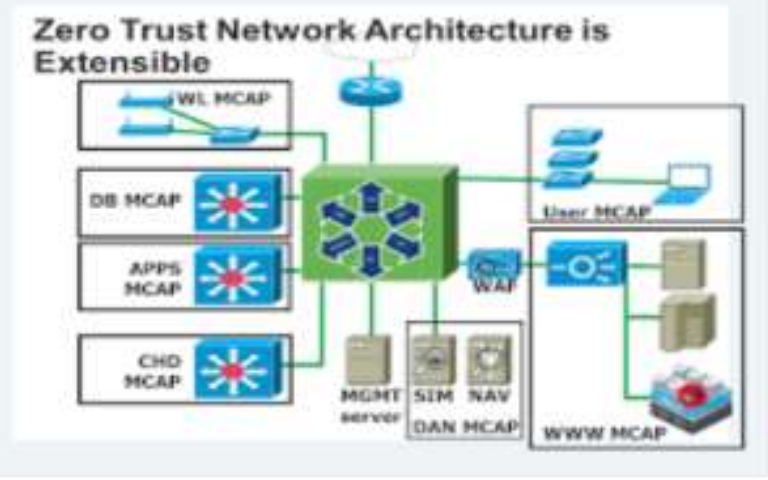

Fig.5. Extensible network architecture .

This is an pattern of a set of connections that is scalable and can be superior than before in any technique we want or necessitate

\section{B. Sanctuary benefits of Nought Conviction :}

Nought Conviction is a way of thinking that acquires countless focal points a few levels to the organization. In this way, I accept that the eventual fate of digital sanctuary experiences this model. As indicated by [8] Zero accepts gives sanctuary and great business results. This adaptation conveys a sizeable endeavor worth like more organization perceivability protective your supporter records and venture. In a "front-stop" frame of mind Zero acknowledge as valid, by means of stay away from money related charges in sanctuary reviews, protecting an extraordinary acknowledgment toward various associations. In a "back-stop" point we've diminished time to rupture discovery and get perceivability into the majority of your shared interchange by investigating the client solicitation, contraptions, and data. Decreasing the unpredictability of the sanctuary mountain is a mind blowing prop up for the system safeguarding group to convey insurance and great conclusion-character involvement by means of this, we container be totally refreshed? Obviously not. A few assaults against Nought Conviction systems are very much alleviated, while others we can just recognize the assault. No model is impeccable and $100 \%$ compelling yet we can decrease the effects brought about by an assault.

\section{BEYOND CORP BY GOOGLE}

Past Corp is a production sanctuary representation of configuration Nought Conviction composes in Google. By shifting framework edge right of entry gearshift for individual contraptions and customers, Beyond Corp empowers agents to work even more steadily in any zone lacking the prerequisite for a standard VPN fundamentally, accordant to [9] Google Beyond Corp is another representation that reasons benefits in the shared framework, rather, get to simply reckon upon the accreditations of the customer and the contraption. Not, by means of standing whether it is in a home framework, a hotel or a bistro. All passage to enormous business resources is totally confirmed, totally endorsed, and totally encoded subject to contraption state and customer accreditations. Past Corp can actualize fine-thorough work admittance to poles apart bits of huge business property Beyond Corp contains many planning portions to ensure that solitary fittingly approved campaign and customers are affirmed to get to the basic undertaking coatings (figure 7).

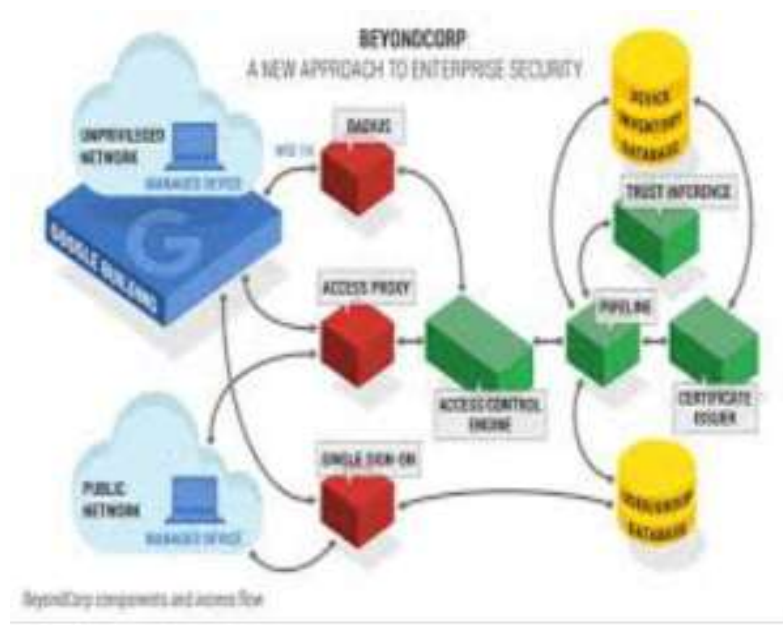

Fig.6. Beyond Corp components and Access flow

during this representation, all of the strategy by and large second-hand by the customer are taken care of in a appliance stock catalog in order to have healthier deceivability of the significant number of contraptions, by means of the intention of are second-hand in the framework. Every such datum accumulated about strategy and customers is relied upon to grasp what coatings are second-hand inside and what 
sanctuary game plans should be associated in each coating. It is essential to appreciate the employments of the position and pick who methodologies express organizations during the categorize to have ground-breaking right of entry have power over. Through this, Beyond Corp conveys various favorable circumstances to corporate framework sanctuary by keeping the business enduring. Past Corp advantages Stay up, by means of the most recent, by means of the

- Most recent programming Keep up a stock of representative

- Gadgets Screen all endpoints and log al

- traffic Just impart over completely encoded

- Channels Fuse multifaceted AUTH

- Kill Static accreditations

However, not all models are $100 \%$ proficient there are likewise a few troubles that may show up in the usage of this sort of model. These troubles may differ contingent upon the territory of movement of the organization itself. Contingent upon the territory of the organization, a few sellers need system access inside the undertaking so as to keep up introduced items or give direct administrations, making access the executives troublesome.

\section{CONCLUSION OF CYBER SANCTUARY}

A domain of rising sanctuary that has been feel in continuous tenner as an exponential function stress since the amount of procedure related, by means of the Web is growing essentially, by means of for all intents and purposes 90 percent of the absolute masses anticipated to be related, by means of the Web as a result of 2030. Additionally, , by means of this, regular sanctuary representations are winding up dynamically unfeasible payable to the maturity in the advancement of the assail and the transfer the edges of PC frameworks. , by means of this circumstance, at hand was a necessitate an additional sort of demeanor and come within reach of on data sanctuary. Nought Conviction rises up out of the need to unravel data sanctuary. , by means of out a direct use formula, along these lines of speculation relies upon "never trust, reliably check". This is the commencement of the peculiarity in the outlook abstaining from the expectation of our framework. Nought Conviction division stage is the reason of any Nought Conviction action that empowers us to shatter the framework hooked on scaled down scale division, empowering us to change our needs, by means of out reconstructing our entire framework. Nowadays we have quite recently watched a couple of associations subsequent this kind of model since they fetch various focal points. Solitary of these personal belongings is Google Beyond Corp. Past Corp is the Google-organized business course of action that empowers customers to work wherever, by means of out VPN

\section{ACKNOWLEDGMENT}

Author would like to articulate genuine appreciation to executive and principal of S R Engineering College, for their support and encouragement to carry out the research work.

\section{REFERENCES}

1. Gilman E., Barth D.: Nought Conviction Networks, O'Reilly, (2017)

2. Sivaraman R.: "Nought Conviction Sanctuary Model". S3tel Inc, White Paper (2015)

3. Williams C.: Nought Conviction Sanctuary, Centrify Special Edition. John Wiley \& Sons, Inc., Hoboken, New Jersey (2019)

4. Osorio de Barros G.: "A Economia da Cibersegurança", Gabinete de Estratégia e Estudos, Ministério da Economia(2018)

5. Morgan S.: "Cybersanctuary Market Reaches $\$ 75$ Billion In 2015; Expected To Reach \$170 Billion By 2020", Forbes (2015)

6. Gowdiperu Sucharitha, Srinivas Aluvala, Deepika Vodnala, Y.Nagendar, "A Survey on Mobile Ad-hoc Social Networks for Efficient Data Query in Intermittently Connected System" in International Journal on Innovative Research in Computer and Communication Engineering, Volume 3, Issue 11, Page No(s) 11831 1183, NOV. 2015, [ISSN (Print):2320 - 9801], DOI: 10.15680/IJIRCCE.201

7. Kindervag J.: Build Sanctuary Into Your Network's DNA: The Nought Conviction Network Architecture, Forrester (2010)

8. Kindervag J.: Clarifying What Nought Conviction Is and Is Not (2018)

9. D.Mahesh, Y.Nagendar, "DIFFICULTIES OF MANET FOR MOBILE SOCIAL NETWORKS" in International Journal on Computer Science and Engi, Volume 10, Issue 1, Page No(s) 1 - 6, JAN. 2018, [ISSN (Print):2229-5631, ISSN (Online): 0975-3397]

10. Akamai: "The 6 Business and Sanctuary Benefits of Nought Conviction ." White Paper (2018)

11. Y.Nagendar, Y. Chanti, B. Vijay Kumar, D.Mahesh, "Protection Issues and Disputes in Wireless Sensor Networks" in International Journal on Computer Science and Engineering (IJCSE), Volume 9, Issue 12, Page No(s) 706 - 713, DEC. 2017, [ISSN (Print):2229-5631, ISSN (Online): 0975-3397]

12. Ward R., Beyer B,: "BeyondCorp A New Approach to Enterprise Sanctuary". Usenix, vol. 39:6 (2014)

13. Gowdiperu Sucharitha, Srinivas Aluvala, Deepika Vodnala, Y.Nagendar, "A Survey on Mobile Ad-hoc Social Networks for Efficient Data Query in Intermittently Connected System" in International Journal on Innovative Research in Computer and Communication Engineering, Volume 3, Issue 11, Page No(s) 11831 . 1183, NOV. 2015, [ISSN (Print):2320 - 9801], DOI: 10.15680/IJIRCCE.201

14. Srinivas Aluvala, K. Raja Sekar,, Deepika Vodnala, "A Novel Technique for Node Authentication in Mobile Ad-hoc Networks" in Elsevier - Perspectives in Science, Volume 8, Issue 1, Page No(s) 680 - 682, SEP. 2016, [ISSN(Print):2213-0209], DOI:10.1016/j.pisc.2016

15. P.Kumara Swamy, Dr.C.V.Guru Rao, Dr.V.Janaki, "Functioning of secure key authentication scheme in" in International Journal of Pure and Applied Mathemat, Volume 118, Issue 14, Page No(s) 27 - 32, MAR. 2018 , [ISSN(Print):1314-3395]. 


\section{AUTHOR's PROFILE}

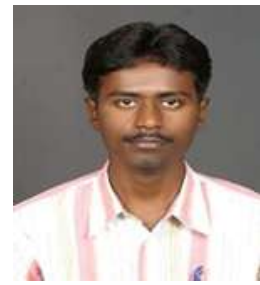

Nagendar Yamsani received Master's degree in Computer Science and Engineering in 2009 from Jawaharlal Nehru Technological University, Hyderabad, India. He is Pursuing Ph.D. degree in the stream of IoT in Computer Science and Engineering at K L University, Guntur, Andhra Pradesh, India. He has 9 years of teaching experience. Currently he is working Assistant Professor in the Department of Computer Science and Engineering in $\mathrm{S} R$ Engineering College (Autonomous), Telangana, India and Coordinator, S R Research \& Development Center. He has published Eighteen International Journals and Three International Conference Papers. His research areas include Networks Sanctuary, Automata and Data Mining. He is a Life Member of Indian Society for Technical Education (ISTE).

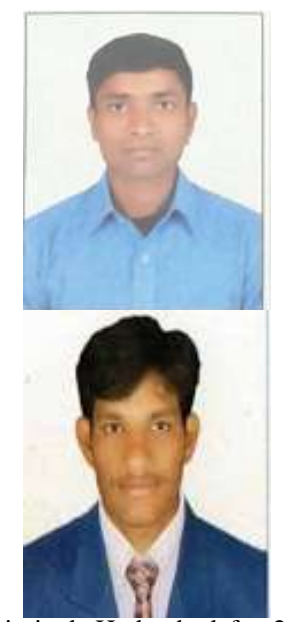

YerrollaChanti received Master's degree in Computer Science and Engineering in 2016 from Jawaharlal Nehru Technological University, Hyderabad, India. $\mathrm{He}$ has the teaching experience of 3 years. Currently, he is working as Associate Professor in Computer Science and Engineering Department at S R Engineering College, Warangal, India. His research areas include Networking, Big Data Analytics.

Vijay Kumar Bura received his Bachelors Degree (B.Tech) in Computer Science Information Technology from JNTUH in 2006 and Master'sdegree (M.Tech) in Software Engineering form Jawaharlal Nehru Techno-logical University, Hyderabad, Telangana, India in 2011. He worked as Software Engineer at ITP Software India Private Limited, Hyderabad for 2 years. He developed various web coatings for different clients. He worked as Asst. Prof. in the Dept. of IT, SVS Institute of Technology, Warangal for 2 years. Presently he is working as Assistant Professor in the Department of Computer Science and Engineering, S R Engineering College (Autonomous), Warangal Telangana, India. As a mentor, he represented a team to participate in CISCO IoT Hackathon 2017 held at Trident Group of Institutions, Orissa, The team idea was selected for "Best Jury Award" and secured RUNNER UP position.

https://www.facebook.com/Cisco.India.IoT.Hackathon/

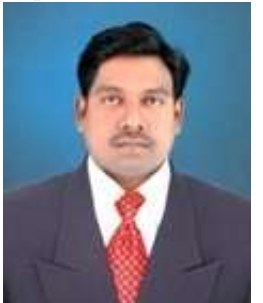

SrinivasAluvala received his Masters degree in Computer Science and Engineering (M.Tech) form Jawaharlal Nehru Technological University, Hyderabad, Telangana, India in 2010. He is Pursuing Ph.D. degree in the stream of Mobile ad-hoc networks in Computer Science and Engineering at KL University, Guntur, and Andhra Pradesh, India. He has 10 years of teaching experience. Currently he is working as Assistant Professor and heading the Department of Computer Science and Engineering in SR Engineering College (Autonomous), Telangana, India. He is executing a research project titled "Development of Adhesive Tactile Walking Surface Indicator for Elderly and Visually Impaired People".

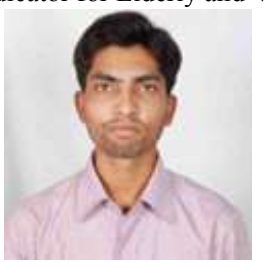

Mahesh Dandugudum received Master's degree in Computer Science and Engineering in 2016 from Jawaharlal Nehru Technological University, Hyderabad, India. He is an Assistant Professor at the S R Engineering College, Warangal from 2017 to till date. His research areas include Networking, IoT 